\title{
Container Ship Investment Based on Real Option
}

\author{
Yu Siqin ${ }^{1, a}, J_{i}$ Bin $^{1, b}$, Chen Jinhai ${ }^{1, c}$ \\ ${ }^{1}$ Shanghai Maritime University, China \\ aysq@shmtu.edu.cn, bsqhuang@163.com, cjinhaichen2005@163.com
}

Keywords: Real option, Container ship investment, Oligopoly

\begin{abstract}
This study investigates liner companies' timing of investment and sealing up container ships based on real option theory. The Dixit model is adopted to find out a pair of trigger prices for entry and exit with the assumption freight rate obey Geometric Brownian Motion. More new ship-building orders and entrants lead to lower future freight rate in the oligopoly liner shipping market. This model is tested empirically basic on the data of a 9000 TEU container ship on Far EastEurope route and the result is positive comparing to the number of ship orders. Liner companies' should make decision base on the freight of the ship in operation. Therefore, ship investment should be made at the new ship order trough and freight trough.
\end{abstract}

\section{Introduction}

Ship investment is crucial to shipping companies' survival and development. At the beginning, the study of ship investment's decision-making focused on methods like DCF, investment payoff period, etc. ${ }^{[1]}$, and later it also contains the external factors to obtain a comprehensive evaluation ${ }^{[2]}$. The real option has been successfully applied in the fields of resource development, research and development project evaluation, and it is being gradually applied into ship investment. Bendall H.B. and Stent A.F. (2005), through the empirical analysis of the different ways of allocating container ships of Singapore-Port Klang-Penang route, selected the optimal scheme and performed sensitivity analysis to it ${ }^{[3]}$. Ruiqing Shao (2005) summarized eight kinds of real option of ship investment, and revealed the value of the decision-making method based on real option ${ }^{[4]}$. Yaoding Li(2007) established the real option model based on shipping price random walk and mean reversion, and analyzed the optimal rule of ship investment, and performed empirical analysis ${ }^{[5]}$. Lv Jing, etc.(2010) established binary tree pricing model of ship investment based on freight fluctuation simulation by Monte Carlo method $^{[6]}$. Shiyuan Zheng (2011), by using real option game theory, established a bulk ship investment model under the random freight fluctuation, and deduced the optimal investment rule with carriers' homogeneous competition and differentiated competition ${ }^{[7]}$. This paper uses the real option theory to study the critical value of liner companies' investment and ship sealing-up, also considers the impact of new shipbuilding order quantity. Empirical analysis is adapted to verify the effectiveness of the proposed method by the actual data.

\section{Ship Investment Model Based on Real Option}

Basic Assumptions. Assume the exogenous fluctuate container liner freight obeys the continuous-time Geometric Brownian Motion as the original statement ${ }^{[8]}$ and several empirical analyses $^{[9][10]}$ shew its rand walk. Li Dingyao (2007) described the variations of shipping price with Geometric Brownian Motion ${ }^{[5]}$, which express

$$
d P=\mu P d t+\sigma P d z
$$

$\mu$ and $\sigma$ are the drift rate and standard deviation, $d z$ is the Standard Brownian Motion. Assume enterprises can enter into or exit from the container liner transport market freely, and price can't be controlled in the long term. There is no transaction cost or risk-free excess profit in transport market. Ship investors are "brokers" and are risk-neutral. The market risk free rate is fixed and non-random. 
Assume $\mathrm{K}$ is the price of ship; $\mathrm{t}$ is the unit operating time; $\mathrm{T}$ is the ship's duration. The sunk cost is $I$; $E$ is the exit cost. The variable transport cost per unit of the enterprise after entering into the industry is the same with that of the others', and is named $\mathrm{C}$; $r$ is the market risk free rate; the transport price is $\mathrm{P} . \mathrm{P}_{\mathrm{H}}$ and $\mathrm{P}_{\mathrm{L}}$ are triggers of entry and exit respectively.

The Real Option Model. Dixit's (1989) model $^{[11]}$ is adapted to study the trigger price of new entrants. After purchasing ships with and being put into operation, profit obtained from the shipping operation is $\mathrm{V}$. Liner companies can seal up ships until the freight rebounds. 1 indicates that the enterprise has entered into the industry while 0 is not. $V_{0}(P)$ and $V_{1}(P)$ indicate the expected NPV of waiting and operating at the price of $\mathrm{P}$.

Liner companies keep waiting when the freight is under $\mathrm{P}$, the assets used for investment will continue to be held. At this point, the liner companies have no operating profit but the expected capital gains $^{(1)}$, equal to the opportunity cost of the assets, which means $E\left[d V_{0}(P)\right] / d t=r V_{0}(P)$. According to the ITO lemma, the assets return equilibrium equation in waiting state and incumbent enterprises are

$$
\left\{\begin{array}{l}
\mu P V_{0}^{\prime}(P)+\frac{1}{2} \sigma^{2} P^{2} V_{0}^{\prime \prime}(P)-r V_{0}(P)=0 \\
\mu P V_{1}^{\prime}(P)+\frac{1}{2} \sigma^{2} P^{2} V_{1}^{\prime \prime}(P)+P-C-\frac{K}{m}-r V_{1}(P)=0
\end{array}\right.
$$

According to the value matching and smooth pasting conditions, with the respective option values of the freight rate is 0 or infinitely great, the solutions of entry and exit price respectively are

$$
\left\{\begin{array}{l}
P_{L}=\frac{r-\mu}{r} \frac{\beta_{2}}{\beta_{2}-1}(C-r E) \\
P_{H}=\frac{r-\mu}{r} \frac{\beta_{1}}{\beta_{1}-1}\left(C+\frac{K}{m}+r I\right)
\end{array}\right.
$$

In the solution,

$$
\left\{\begin{array}{l}
\beta_{1}=\frac{1}{2}-\frac{\mu}{\sigma^{2}}+\sqrt{\left(\frac{\mu}{\sigma^{2}}-\frac{1}{2}\right)^{2}+\frac{2 r}{\sigma^{2}}}>1 \\
\beta_{2}=\frac{1}{2}-\frac{\mu}{\sigma^{2}}-\sqrt{\left(\frac{\mu}{\sigma^{2}}-\frac{1}{2}\right)^{2}+\frac{2 r}{\sigma^{2}}}<0
\end{array}\right.
$$

\section{Oligopoly and Model Modification}

The influence of the entry on the price should also be considered. Container liner transport is an oligopoly market $^{[12]}$, which means the added capacity and new entrants will inevitably break the market balance and trigger price war. The goals of profit or market share maximization of different liners make competition more complex. Assume that two liner companies compete on the same liner route, one company, S1, market share maximization; the other one, S2, profit maximization. The market demand is $Q=Q_{0}-a P$. When the new entrant, S3, comes into the market, S1 still occupies the demand q1, and S2 and S3 implement oligopoly pricing. According to the Cournot model, the two companies share the rest of the market equally, and the equilibrium price is $P_{2}=P_{3}=\left(Q_{0}-q_{1}+a C\right) / 3 a$. The market price decreases with the growing number of enterprises who aim at maximizing profit, and with the increase of the total capacity of the enterprises that target at capacity utilization maximization.

\footnotetext{
${ }^{1}$ Here price changes should be the new ship price or the same-age ship price changing with time sequence, not a ship price changing with time sequence.
} 
Real option indicates the price's upward deviation making ship investment profitable with the potential hypothesis of expected freight rate and ship price increasing according to the historical growth rate based on the present situation. However, the freight rate and ship price trend to return to average in long run.

Oversupply results in the rate drop. The demand has great uncertainty while the supply can be estimated by the ship orderbook. When the new ship orders increase greatly and far above the average rate, the future freight rate will decline inevitably. Once the shipbuilding is completed, the critical price entry to the market is no longer $\mathrm{P}_{\mathrm{H}}$, but $\mathrm{P}_{\mathrm{L}}$. Built ships can either be used by existing liner companies to seize more market or become the new liner company capacity, which both lead to rate drop.

\section{Empirical Study and Sensitivity Analysis}

Parametric Hypothesis. Shipping companies' operating costs include ship, container and management costs. Ship cost includes fixed, operating and voyage cost. Fixed costs includes depreciation and capital cost. Assume 25 years $^{(2)}$ straight-line depreciation and the market risk free return is $8 \%$, the annual fixed cost will be $K / 10.68$ USD per year. The operating cost is about $\$ 420$ per TEU per year ${ }^{3}$. Voyage costs include fuel cost, port charge and canal fee. Fuel cost of each voyage is supposed to be $0.425 \mathrm{P}_{0}$ USD/TEU for a 9000TUE container ship base on the research of Theo and Bert (2008) ${ }^{[13]}$ and Theo and Pierre $(2011)^{[14]}$. $\mathrm{P}_{\mathrm{o}}$ is the fuel price (Singapore IFO380 price). The port charge is 304 USD/TEU per year. The Suez Canal fee is assumed to be $\$ 600000$ base on Wang Mingliang's (2012) estimation ${ }^{[15]}$. Terminal handling charge is not included in the freight rate, which will be offset by THC. The container and management cost are 89 dollars/TEU and \$28/TEU respectively ${ }^{[13]}$ as they are constant and small.

Quarterly data arithmetic averaged from Clarksons's monthly price index of 8500-9100 TEU container ships from 2006 to 2012 is applied as new ship-building price. The container liner freight income sequence $(\mathrm{P})$ equals the product of the numbers of slots and voyages, and the sum of the freight rate ${ }^{(4)}$ and the load factor of European eastbound and westbound container, which are $35 \%$ and $85 \%$ respectively. Assume that $E=I=\$ 5000000$.

The Empirical analysis. Container ships' annual operating income sequence follows Geometric Brownian Motion, and the parameter estimation can use maximum likelihood method ${ }^{[16]}$. The results are annual drift rate $\mu=1.90 \%$ and standard deviation $\sigma=25.78 \% . \beta_{1}=2.5249, \beta_{2}=0.9537$. According to the historical data of fuel price, new shipbuilding price and freight rate, the relationship between freight income sequence and entry, exit freight is shown in figure 1 . When $P>P_{H}$, it is the time for investment, such as 2006, 2007 and 2010.

\footnotetext{
(2) According to the 2011 annual report, the container ship depreciation life of COSCO, "CSCL", OOCL, etc is 25 years.

${ }^{8}$ Date source: Drewry report "Ship Operating Costs Annual Review and Forecast 2012/13".

${ }^{(7)}$ Container liner freight was summed up according to the data of Ci-online statistics of quarterly data from 1993 to 2009, Container Freight Quarterly Report from 2010 to 2012, World Container Index(WSI) and Shanghai container freight index(SCFI).
} 


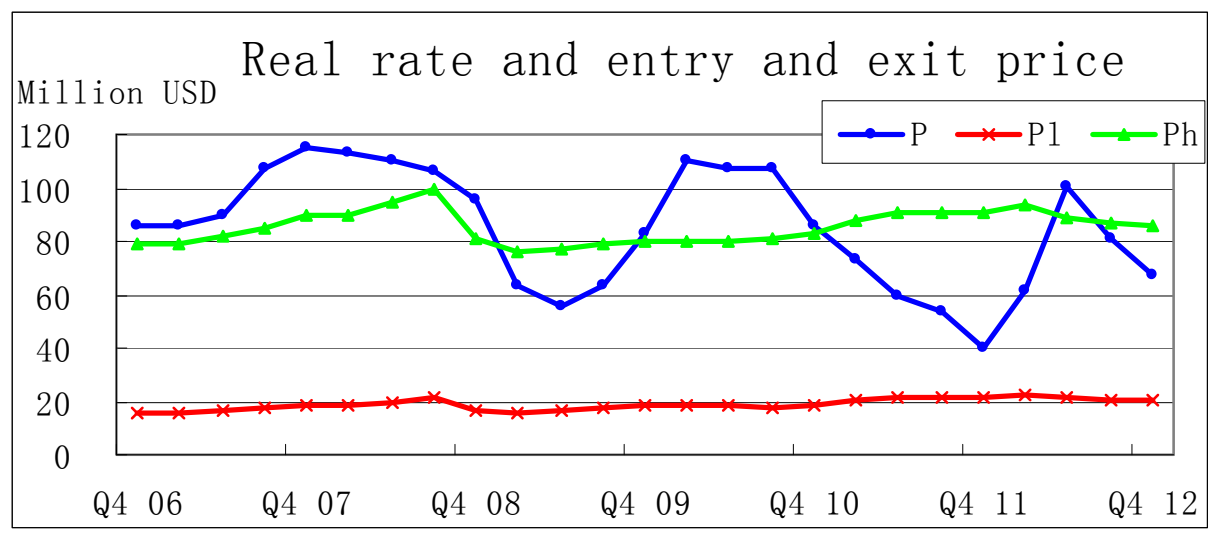

Figure.1. Annual revenue as price fluctuate around trigger of entry but over exit

Data sources: Clarksons

Ship order data prove that investors also do. In 1997-2002, the proportional relation between freight and orders is obvious. The rate and order quantity remained high from 2003 to 2007. New ship orders would have been higher in 2008, if there hadn't been the global financial crisis. In 2011, shipowners "picking the bottom of the falling market" lead to the order boom.

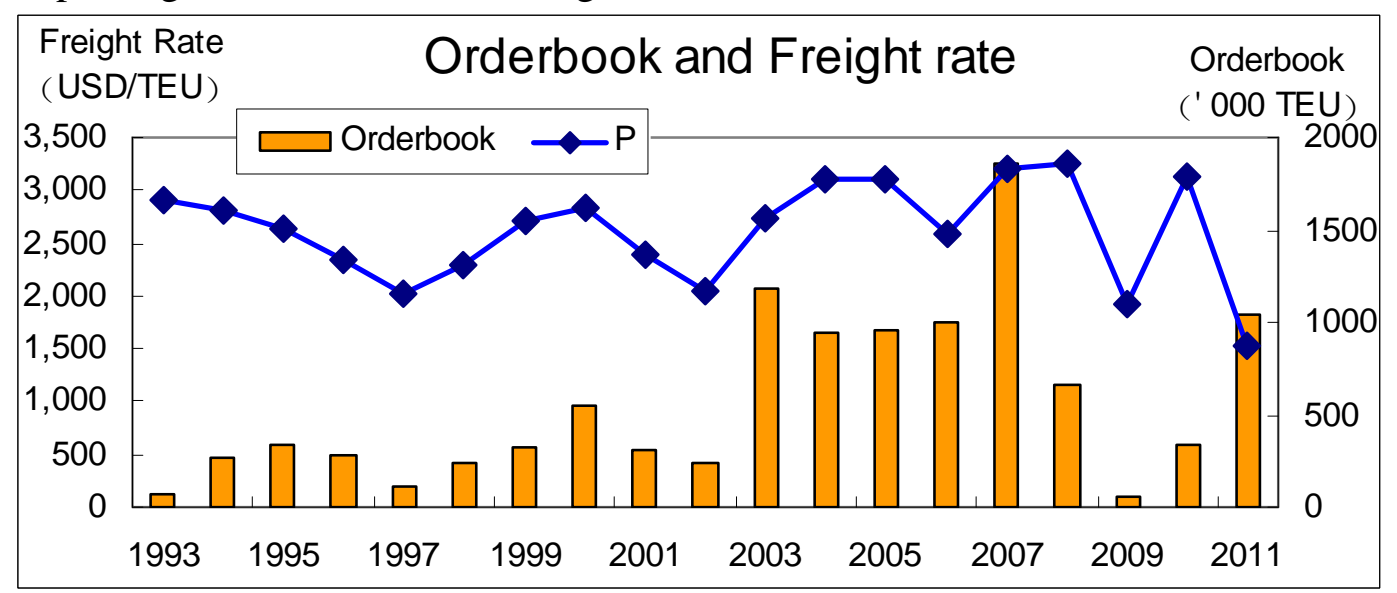

Figure.2. Orderbook always goes the same way with Freight Rate

Note: the freight refers to the Far East-European westbound rate

Data sources: Clarksons

The investors' decision-making should not be based on the current rate, instead of the freight after ships putting into operation. In the long term, freight will not rise or fall sharply and constantly, but fluctuates near the mean value. Therefore, ship investment is most profitable when the freight rate is at the lowest point. In a medium run, the freight has a periodic fluctuation, so it is most profitable to enter into the market when freight rates increase and exceed the cost. In the short-term, the capacity input will lead to the freight rate's falling. So the capacity should be input gradually when the traffic volume rebound rapidly. Correspondingly, ship investment should be made when the economy starts to recover.

\section{Conclusion}

This paper studies the time of ship investment and sealing-up of liner companies by using the real option theory. Firstly, according to the assumptions that the freight follows Geometric Brownian Motion, it solves the the critical value of freight entering and exiting by means of Dixit's real option model. Secondly, it further considers the situation of container liner transport market oligopoly, and analyses the new shipbuilding order and the influence of new entrants on future equilibrium rate. Thirdly, it calculates the ship investment critical rate according to cost and income data of $9000 \mathrm{TEU}$ container ships on Far East-European route.It also verifies the effectiveness of the model through the ship orders and the comparison with the actual rate. Fourthly, the decision-making of liner companies 
should be based on the freight when ships are put into operation. Therefore, ships should be invested when the in new ship order quantity and the rate are at a low point.

\section{Acknowledgments}

This research was supported by The Research Fund for the Doctoral Program of Higher Education from Ministry of Education. Project Number: 20113121110003.

\section{References}

[1] Frankel, Ernst G, Management and operations of American shipping, Auburn House,1982.

[2] Ruiqin Shao, Summary of international shipping investment, Journal of transportation engineering,4(2003)116-120.

[3] Bendall H B., Stent A F, Ship investment under uncertainty: Valuing a real option on the maximum of several strategies, Maritime Economics \& Logistics, 7(2005)19-35.

[4] Ruiqin Shao. Study of international ship investment theory, Tongji University, 2005.

[5] Yaoding Li. Ship investment under uncertainty, Shanghai maritime university, 2007.

[6] Jing Lv, Xiaoxing Gong, Linda Yang, Study of ship investment based on real option, Journal of chongqing jiaotong university,9(2010)474-479.

[7] Shiyan Zhen. Study on Investment Decision about Dry Bulk and Oil Ship under Stochastically Fluctuating Shipping Markets, Shipbuilding of China,1(2011) 225-234.

[8] Zannetos Z S, The theory of oil tankship rate, Massachusetts Institute of technology,1953.

[9] Berg-ANDREASSEN J A, Some properties of international maritime statistics, Maritime Policy and Management,23(1996)381-395.

[10] KAWSSANOS M G, NOMIKOS N K, The forward pricing function of the freight futures market, The journal of futures markets,3(1999)353-376.

[ 11 ] Dixit, A, Entry and exit decisions under uncertainty, Journal of Political Economy,3(1989)620-638.

[ 12 ] Christa Sys, Is the container liner shipping industry an oligopoly?,Transport Policy,16(2009)259-270.

[13] Theo E. Notteboom, Bert Vernimmen, The effect of high fuel costs on liner service configuration in container shipping, Journal of Transport Geography,5(2008)1-13.

[14] Theo Notteboom, Pierre Cariou, Bunker Costs in Container Liner Shipping: Are Slow Steaming Practices Reflected in Maritime Fuel Surcharge?, Shipping Intermodalism \& Ports-ECONSHIP 2011, Chios, Greece, June 2011.

[15] Mingliang Wang, The Suez canal cost and saving measures, Containerization, 5(2012)1-4.

[16] Lo Andrew W, Maximum Likelihood Estimation of Generalized Ito Processes with Discretely-Sampled Data, Econometric Theory, 4(1988)231-247. 